\title{
Professores de Matemática no Mato Grosso: um Olhar por Meio de um Personagem
}

\author{
Mathematics Teachers in Mato Grosso: a Look through a Character
}

\author{
Kátia Guerchi Gonzales ${ }^{\mathrm{a} *}$; Luiz Carlos Pais ${ }^{\mathrm{b}}$
}

\begin{abstract}
"Universidade Estadual Paulista “Júlio de Mesquita Filho", Programa de Pós-Graduação Stricto Sensu em Educação para a Ciência.
bUniversidade Federal de Mato Grosso do Sul, Programa de Pós-Graduação Stricto Sensu em Educação Matemática.

*E-mail: profkatiaguerchi@gmail.com
\end{abstract}

\begin{abstract}
Resumo
A pesquisa teve como objetivo discutir a formação de professores de Matemática no contexto de Mato Grosso ao final do século XIX e início do século XX. Entender quem eram os professores que ensinavam Matemática e a formação que estes possuíam é fundamental, pois foram tais protagonistas, que deram sentido para as construções do passado da matemática escolar. Para isso, lança-se mão de elementos históricos e culturais através de fontes como: leis educacionais, regulamentos da instrução pública, relatórios de presidentes da província e dos diretores da instrução pública. A partir dessas fontes se produz um discurso analítico com base no referencial teórico-metodológico associado aos conceitos propostos por André Chervel e outros autores, que compartilham do programa de história das disciplinas escolares. Por meio das análises, verifica-se não só a formação dos professores, que ensinavam Matemática ao final do século XIX e início do século XX no Mato Grosso Uno, mas também como ocorria o ensino e as reformas da época. Ainda se nota que havia grande presença de engenheiros, militares e políticos dentro das instituições públicas de ensino, principalmente, no que diz respeito aos professores, que ensinavam Matemática. Essa afirmação é notável, desde o registro que se tem do professor que assumiu uma das primeiras cadeiras destinadas a Matemática no Mato Grosso Uno, já que tal professor foi o Tenente João Baptista Castro Morais Antas, que estudou na Acadêmica Militar da Corte, tinha formação em Engenharia Civil e foi um dos primeiros doutores em Ciências e Matemática.
\end{abstract}

Palavras-chave: Formação de Professores. Educação Matemática. História da Educação Matemática. Mato Grosso.

\begin{abstract}
This research aimed to discuss the Mathematics teachers qualification in the context of Mato Grosso in the late nineteenth and early twentieth century. Understanding who the teachers who taught Mathematics were and the training they had was fundamental because they were such protagonists that gave meaning to the school mathematics past qualification. So to make this happen, e historical and cultural elements were used through sources such as: educational laws, public education regulations, reports of provincial presidents and public education directors. From these sources an analytical discourse was produced based on the theoretical-methodological framework associated with the concepts proposed by André Chervel and other authors who share the same history program of the school subjects. Through the analyzes, it was verified not only the teachers' qualification who taught Mathematics in the late nineteenth and early twentieth century in Mato Grosso Uno, but also how the teaching and reforms of the era were given. Also, it was noticed that there was a great presence of engineers, military and politicians within the public institutions of education, especially with respect to the teachers who taught Mathematics. This statement is remarkable, since the record that we have of the teacher who took one of the first Mathematics chairs in Mato Grosso Uno was professor Lieutenant João Baptista Castro Morais Antas, who studied at the Military Academic of the Court, had training in Civil Engineering and was one of the first PhDs in Science and Mathematics.
\end{abstract}

Keywords: Teacher Training. Mathematical Education. History of Mathematics Education. Mato Grosso

\section{Introdução}

Este artigo tem como objetivo principal discutir a Formação de Professores de Matemática no contexto matogrossense do século XX. Contudo, é fundamental ressaltar que discorrer sobre a formação de professores de Matemática, atualmente, é diferente de discorrer sobre a formação dos professores, que ensinavam Matemática no passado. Tal motivo se deve à criação de cursos específicos para formar professores de Matemática, que começaram a se propagar a partir de 1930, por meio da Reforma Francisco Campos, que trouxe como contribuição o Estatuto das Universidades Brasileiras, instituindo o regime universitário. Assim, os cursos destinados a formação de professores secundários foram instalados a partir do estatuto, que previa a necessidade das instituições universitárias possuírem pelo menos três das seguintes faculdades: Medicina, Engenharia e Educação, Direito, Letras e Ciências.

Nesse sentido, para se ter uma ideia da natureza restrita e situada da criação e instalação de cursos de graduação em Matemática, cita-se o Estado de São Paulo e sua capital, que a partir da legislação vigente à época, criou em 1934 na Universidade de São Paulo, na Faculdade de Filosofia, Ciências e Letras - FFCL, o primeiro curso dedicado para a formação de Matemática, porém no interior deste mesmo Estado, os cursos de graduação em Matemática começaram a serem instalados somente a partir da década de 1940 (MARTINS-SALANDIM, 2012). Nos demais Estados, a 
criação específica de cursos de graduação em Matemática foi ainda mais tardia, o que leva ao pesquisar a formação de professores, que ensinavam Matemática antes deste período, em trilhar outros caminhos, não olhando apenas a criação de cursos de graduação.

Em outras palavras, abordar sobre o desfecho da formação de professores em outros Estados, como o Mato Grosso, requer ir além das instituições, da criação de cursos de graduação de Matemática e de olhar o contexto social e histórico da época, em que se destina a pesquisa. Torna-se fundamental entender, também, quem eram os professores que ensinavam Matemática e a formação que estes possuíam, pois tais protagonistas deram sentido às construções do passado da matemática escolar.

Dessa maneira, considera-se que os principais agentes educativos, professores e alunos são fundamentais para dar vida à cultura escolar possibilitando materializar a finalidade de uma disciplina escolar. Além do mais, olhar para um determinado personagem possibilita, por meio da vida deste compreender o contexto social, histórico e político no qual este esteve inserido, por meio das relações de poder existentes. Baseando-se em historiadores como Guinzburg (2006), que também lançam mão de personagens com o intuito de compreender determinado contexto, época e problema. É claro que as histórias locais não são generalizáveis, assim, não se deve generalizar um caso particular de um personagem para os demais, porém ao estudar tais sujeitos, além de permitir compreender o contexto sócio-histórico como já citado, possibilita-se entender as criações de táticas dinâmicas, que estes desenvolveram para sobreviverem em determinada sociedade, dentro de determinado sistema - neste caso, o sistema escolar.

Pesquisas deste tipo, embora centradas no professor, ou nas práticas, revelam não somente como foram feitas as apropriações de currículos, programas e métodos, uma vez que estes revelam também a legislação, a matemática escolar e a cultura escolar de um determinado período entre outros tantos objetos, que podem ser explorados, por meio da variedade de fontes e conexões feitas em pesquisas dessa natureza.

Estudar a formação dos professores, que ensinavam Matemática no Mato Grosso ao final do século XIX e início do século XX, que é aqui o foco, requer um olhar aos agentes escolares, uma vez que como já salientado, não havia cursos de graduação específicos. Dessa forma, levantam-se alguns questionamentos, que envolvem a formação de professores de Matemática no Mato Grosso: Qual era a formação do professor que ensinava Matemática no Ensino Secundário, no Mato Grosso, antes de existirem cursos de graduação em Matemática? Qual foi a primeira cadeira de Matemática no Mato Grosso e qual era a formação do professor que assumiu esta cadeira? Qual era a formação dos professores de Matemática que atuavam no Liceu Cuiabano?

\section{Desenvolvimento}

\subsection{Referencial Teórico-metodológico}

O historiador André Chervel desenvolveu uma teoria sobre a História das disciplinas escolares ${ }^{1}$ que é um campo de pesquisa, em que o trabalho está inserido. Por isso, tomase como base o referencial proposto por Chervel (1990) para fundamentar a pesquisa que foi realizada. Adotada esta perspectiva, utilizam-se os conceitos de Disciplina, Vulgata e Cultura Escolar, segundo Chervel, seus pares e o ponto de vista do pesquisador.

Outro instrumento teórico que ajudou a conduzir a pesquisa foi o conceito de apropriação, proposto por Chartier (1991). Este instrumento foi imprescindível para se fazer a interpretação dos traços encontrados nas fontes analisadas. Na visão de Chartier (1991, p.180) a apropriação “[...] visa uma história social dos usos e das interpretações, referidas às suas determinações fundamentais e inscritas nas práticas específicas que as produzem". Nessa compreensão, o conceito se revela significativo na condução de estudos como este, que estão inseridos na história cultural.

Os conceitos de estratégia e táticas que aparecem neste trabalho se encontram no sentido proposto por De Certeau (2002). Por isso, se tratam de instrumentos teóricos com os quais se analisam os traços históricos da Formação de Professores de Matemática no contexto de Mato Grosso de outrora. Tais conceitos foram enunciados por Michel de Certeau, no livro Invenção do Cotidiano, em que o autor buscou compreender o que está por trás das relações estabelecidas entre instituições ligadas às práticas escolares.

Apropria-se, também, de instrumentos utilizados por historiadores, acrescentando ao manancial teórico, os conceitos de Marc Bloch, historiador francês, que estabeleceu, pela primeira vez, a noção de "história como problema".

\subsection{Criação de uma das primeiras cadeiras de Matemática no Mato Grosso}

Um dos primeiros registros, a que se teve acesso, sobre o ensino secundário da Matemática na província de Mato Grosso foi a criação de uma cadeira de Geometria na cidade de Cuiabá, conforme Decreto de 11 de novembro de 1831. Esta mesma legislação incluía a criação de uma cadeira de Retórica. São informações contidas no relatório do presidente da província de 1839, em que o chefe do Poder Executivo realizava uma descrição das condições da instrução pública local (REZENDE, 1839).

Entretanto, o fato de existir uma legislação, criando uma cadeira, não garantia que as aulas estivessem acontecendo,

1 Para Chervel (1990) a disciplina escolar é constituída pela combinação, em proporções variáveis, de vários constituintes: ensino de exposição, exercícios, práticas da incitação e de motivação e um aparelho docimológico, os quais, em cada estado da disciplina, funcionam em estreita colaboração, do mesmo modo que cada um deles está em ligação direta com as finalidades. 
pois além do ato legal, havia a necessidade de um professor aprovado para ministrar as aulas, o que não tinha. A partir das anotações de Moacyr (1939), se tem a informação que, em 1835, existiam, na província, apenas cinco aulas avulsas de Ensino Secundário: Latim, Filosofia, Retórica, Francês e Geometria, dentre as quais somente Latim e Filosofia eram, de fato, ministradas, pois, geralmente, essas matérias eram do domínio dos padres, cuja formação humanista priorizava os estudos das línguas, das artes e da Filosofia. As três últimas aulas avulsas - Retórica, Francês e Geometria - estavam vagas por falta de professor disponível.

Conforme Chervel (1990), todo o conteúdo é inserido em um programa de ensino com alguma finalidade. No caso particular de Mato Grosso, a inserção das aulas, aqui mencionadas, que se destinavam ao Ensino Secundário, tem a finalidade de preparar os candidatos aos cursos superiores do império.

As aulas de preparatórios surgem em face às exigências para ingresso nos cursos superiores do império, existentes no século XIX. Inicialmente, existiam as aulas avulsas das matérias preparatórias, que foram providenciadas pelas províncias de São Paulo, Rio de Janeiro, Recife e Salvador, em que havia os primeiros cursos superiores. Estas aulas preparavam os candidatos, que deveriam passar por bancas examinadoras nas localidades nas quais estavam concentrados os cursos (SIQUEIRA, 2000).

No caso de Mato Grosso, em 1844, o presidente da província, Zeferino Pimentel Moreira Freire ressaltou, em sua fala, na Assembleia Legislativa, que havia criado uma cadeira de Geometria, como se lê no seguinte fragmento retirado do Relatório Provincial:

Servindo-me da faculdade que me dá a Lei de criar uma cadeira de Geometria, tenho estabelecido esta aula em uma das casas Arsenal de Guerra, devendo a pessoa encarregada da mesma, lecionar também Aritmética, Álgebra, Trigonometria retilínea e teoria dos logaritmos não só com o fim de habilitar jovens militares que se dedicaram a carreira das armas, como preparar nossa mocidade para os empregos públicos, principalmente aqueles que jogão com contabilidade, nem é possível entender-se Geometria sem terem noções de Aritmética e Álgebra. Reconhecendo no Tenente João Batista de Castro Moraes Antas toda a idoneidade para desempenhar estas funções pelos títulos que apresentou, e exame a que se procedeu na forma da Lei, o tenho nomeado lente desta cadeira, dando-lhe estatutos para seu regime (FREIRE, 1844, p.8).

A cadeira, a qual se refere o presidente da província, era uma cadeira de Geometria, no entanto, também seriam abordados conteúdos referentes à Aritmética, à Álgebra, à Trigonometria Retilínea e à Teoria dos Logaritmos. A composição de conteúdos que o Tenente João Batista de Castro Moraes Antas foi encarregado de ministrar seguia o plano de ensino do Colégio Pedro II, de acordo com o Regulamento $n^{\circ} 08$ de 31 de janeiro de 1838 , fato que permite observar a tentativa de se inculcar traços de outra cultura escolar (JULIA, 2001) que, neste caso, foi proposta pela sede imperial.
O Colégio Pedro II era uma instituição destinada ao Ensino Secundário. Foi criado em 1837 e servia como modelo para os demais Liceus provinciais. Porém, não era levada em conta a cultura de cada local, tendo resultados infrutíferos pelo modo que os outros estabelecimentos se apropriavam de elementos da cultura escolar pertencente à corte, como o plano de ensino, no caso em estudo.

Fato importante é a maneira como o presidente afirma, em necessidade de se ensinar Aritmética e Álgebra antes do ensino da Geometria, ressaltando que os dois primeiros servem como referência para o último. De acordo com o texto de Chervel (1990), essa maneira de sistematizar os conteúdos é importante dentro da disciplina, pois alguns conteúdos passam a ser métodos de outros. Nesse sentido, é significativo ponderar o quanto a Aritmética e a Álgebra passam a ser métodos da Geometria, no que se refere a usar como ferramenta para aprender conceitos geométricos.

Pode-se citar como finalidades da criação de uma cadeira de Geometria o interesse da sociedade em formar, além de militares, candidatos aos empregos públicos. Também havia a intenção de preparar os que fossem trabalhar com contabilidade e, além disso, a preparação dos candidatos para cursos jurídicos. Todos estes fatores são objetivos consideráveis que a sociedade precisava alcançar e, dessa forma, a Geometria se torna imprescindível no contexto escolar daquele momento.

Para ocupar a cadeira de Geometria, era fundamental alguém que dominasse os conteúdos que a compunham, para que fosse possível fazer a articulação entre estes. O professor que foi destinado à missão de ministrá-la foi o Tenente João Baptista Castro Moraes Antas, já referido, que estudou na Academia Militar da Corte por sete anos e tinha a formação de engenheiro civil e Doutor em Ciências e Matemática, título necessário para ser professor substituto na Academia Militar.

Segundo Baroni e Miller (2008), esse título se consagrava aos engenheiros civis, haja vista que mais da metade do curso, oferecido na Escola Militar do Rio de Janeiro, continha conteúdos relacionados à Matemática. O decreto 140, de nove de março de 1842, instituiu o grau de Doutor em Ciências e Matemática e, no dia 28 de maio de 1848, recebem esse título os seis primeiros doutores que defenderam tese, entre os quais podemos citar João Baptista Castro de Morais Antas.

De acordo com nossos levantamentos, há fortes indícios de que o Tenente João Baptista tenha sido o primeiro professor público de Matemática nomeado, oficialmente, na província de Mato Grosso. Entretanto, este professor permaneceu, nesta cadeira, por aproximadamente um ano, solicitando sua demissão no dia $1^{\circ}$ de fevereiro de 1845 e justificando-a pela falta de interesse e procura pela aula, já que havia poucos alunos matriculados e, entre eles, raros obtiveram sucesso durante o tempo que o curso se manteve.

\subsection{Ensino da Matemática no Mato Grosso ao final do século XIX e início do século XX}

No início do século $\mathrm{XX}$, com as novas tecnologias 
surgiram as novas profissões e as disciplinas científicas se tornaram valorizadas, assim novas propostas educacionais se fizeram presentes. Porém, é necessário verificar se tais propostas foram efetivadas no contexto de Mato Grosso e, para isso, recorre-se aos cadernos, contendo textos didáticos, de um professor importante para o ensino da Matemática no Estado. De acordo com Nobre, Teixeira e Baroni (2004, p.178), tal investigação se torna essencial:

Diretamente ligado ao tema história de instituições, está

a história de personagens que atuaram nessas instituições

e deram grande contribuição ao desenvolvimento da

Matemática e da Educação Matemática no Brasil.

Tendo como objeto histórico a cultura escolar, conforme as ideias de Julia (2001), deve-se investigar as normas e as finalidades do contexto escolar, o papel do educador, os conteúdos ensinados e as práticas escolares. Nessa perspectiva, baseados na definição proposta por Julia (2001), no que se refere à cultura escolar, se tem que um dos elementos essenciais a ser pesquisado são as normas e as práticas presentes no contexto escolar a ser analisado. Contudo, o próprio pesquisador ressalta que tais elementos só poderão ser analisados se forem investigados os professores, que deviam obedecer tais ordens.

Para a consecução desta etapa da pesquisa, vale-se do professor Firmo José Rodrigues (1871-1944), que foi protagonista de uma longa trajetória no magistério, e este atuou por cerca de meio século no contexto mato-grossense. Esta constatação foi feita no Arquivo da Casa Barão de Melgaço em Cuiabá, que possui um grande acervo da Família Rodrigues, rico em documentos referentes à vida social, profissional e pessoal do personagem principal em análise. Assim, foram coletados e verificados, por meio de variados documentos, que quase todo o período de sua existência, o professor Rodrigues esteve envolvido com o ensino.

Figura 1- Professor Firmo José Rodrigues

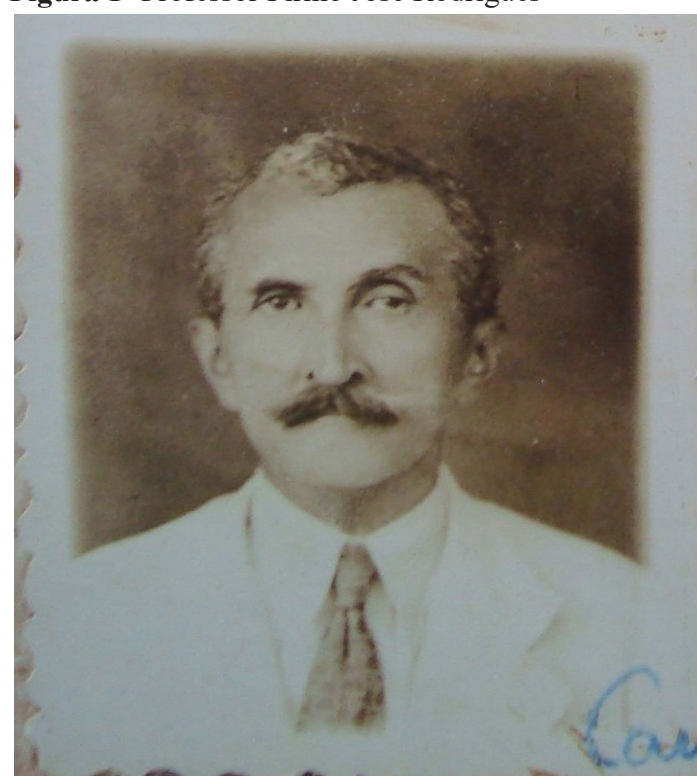

Fonte: Arquivo da Casa Barão do Melgaço
De acordo com as leituras realizadas, o professor é uma fonte fundamental para pesquisas que buscam constituir a história do ensino da Matemática. Na visão de Schubring (2005, p.9):

Ele não constitui um sujeito passivo que recebe os programas e os faz aplicar mas ele representa a pessoa decisiva no processo de aprendizagem. Em minha opinião, a vida profissional do professor representa o melhor meio para ter acesso à realidade histórica do ensino.

Sob esta ótica, a vida profissional do professor Firmo José Rodrigues possibilitou reconstruir o ensino da Matemática e, por esta razão, relata-se a sua trajetória educacional.

Tomando por base os dados biográficos que estão no livro: Figuras e Coisas da Nossa Terra de autoria de Firmo José Rodrigues, que foi publicado em 1959, pela sua filha Dunga Rodrigues, no qual se tem indícios que esse professor, além de militar, estava envolvido com a política de Mato Grosso, conforme se evidencia em seus dados biográficos apresentados na sequência:

Figura 2: Bibliografia do Professor Firmo José Rodrigues

\section{DADOS BIOGRAFICOS}

FIRMO JOSÉ RODRIGUES - Nascido em Cuiabá a $1^{\circ}$ de Junho de 1871 e falecido na mesma cidade, a 16 de Junho de 1944. Major de Artilharia do Exército Nacional. Tomou parte saliente na contra-revolução de 1893, foi à França buscar e guarnecer o Cruzador "Benjamin Constant". Foi professor de Física e Química e Matemática do Liceu Cuiabano e do Liceu Salesiano S. Gonçalo e de Matemática da Escola Normal Pedro Celestino. Presidente do Tiro de Guerra Batista das Neves, Diretor do Extinto Arsenal de Guerra, Comandante da Fôrça Pública do Estado, Vereador e Presidente da Cãmara Municipal de Cuiabá, Deputado Estadual, Vice-Presidente do Instituto Histórico de Mato-Grosso, membro de Escritores Brasileiros em Mato-Grosso (Presidente).

Ccıaborou na "Revista Mato-Grosso", na "Revista da Academia Matogrossense de Letras", na "Revista do Instituto Histórico de Mato-Grosso" e nos jornais: "A Cruz", "O Estado de Mato-Grosso", “O Correio da Semana", "O Mato-Grosso", e na revista "Pindorama".

Publicou um livro em colaboração com o Desdor. José de Mesquita e Rubens de Mendonça: "Bibliografia Matogrossense".

Fonte: Rodrigues (1959, p.6).

Todos os descritos de sua trajetória como estudante e como professor foram possíveis de serem feitos, por meio das crônicas e dos relatos que se tem em mãos e que constam nos livros: Figuras e Coisas da Nossa Terra, nos volumes um e dois. Também foram encontrados alguns elementos no próprio acervo da Família Rodrigues, que já se relata e que está no Arquivo da Casa Barão do Melgaço em Cuiabá - MT. 
O professor Rodrigues nasceu no dia $1^{\circ}$ de Junho de 1871 , em Cuiabá - MT, filho do mestre da Oficina de Serralheiros do Arsenal de Guerra de Cuiabá, Bento José Rodrigues e de Benedita Alves Rodrigues. Iniciou os seus estudos na escola particular do mestre Manuel Leopoldino do Nascimento, com sete anos, descrevendo que tal escola tinha o número reduzido de alunos e que ele gostava muito de estudar nela. No ano posterior, deu continuidade em seus estudos na escola pública do $2^{\circ}$ distrito e seu professor foi Francisco da Costa Ribeiro. Rodrigues, em suas crônicas, descreve a não pontualidade do professor, revelando, no trecho a seguir, uma das práticas comuns na escola.

Morando o professor numa chácara distante e não primando pela pontualidade, os alunos ficavam por muito tempo aos cuidados de um aluno de classe adiantada e que se denominava monitor mor; durante esse tempo reinava na escola a maior anarquia. Dividindo em oito classes, tinham os alunos de cada classe um monitor, com o dever de tomar a lição e aplicar quantas palmatórias quisesse. Então, no argumento da doutrina cristã, era um regalo para o monitor passar bolos. Fiquei odiando esse monitor mor, que, nessa época, era Marçal Faria, hoje general reformado do exército (RODRIGUES, 1959, p.9).

Como Rodrigues iniciou seus estudos aos sete anos e, na época deste relato, ele estava em seu segundo ano, acredita-se que a descrição seja do ano de 1879 . Neste período, uma das práticas escolares das escolas primárias era o trabalho com o método mútuo, que tinha por objetivo ensinar centenas de crianças ao mesmo tempo.

Siqueira (2000) afirma que esse método se originou na Índia, em que a maioria da população era analfabeta, promovido pelo escocês André Bell, em 1797. Porém, o método ficou mesmo conhecido por meio de Joseph Lancaster, que fomentou as ideias de André Bell em vários países. Já no Brasil, o ensino mútuo foi inserido pelo português Antonio José Falcão da Frota, após a Independência, mas antes mesmo de ser utilizado para alfabetizar crianças no Brasil, o método foi adotado no Exército, instruindo vários cadetes.

O método lancasteriano, pressupondo um ensino entre iguais, distribuía as tarefas da seguinte maneira: ao professor, cabia apenas a supervisão, mas nunca de regência que, nesse método, era transferida para os alunos mais adiantados a fim de que fizessem as vezes do professor. Era quase nula a participação do professor cabendo-lhe, apenas, coordenar - apitar quando do término e início - as atividades e atribuir notas. (SIQUEIRA, 2000, p.198).

Os professores escolhiam os alunos mais adiantados, que eram conhecidos como monitores ou decuriões, denominação que se originou pelo fato que o total de alunos era dividido em grupos de dez, ou seja, cada um dos monitores ficava responsável por uma decúria. As aulas aconteciam de modo oral, os monitores colocavam seus manuscritos nas paredes e faziam os alunos repetirem e, ao final, aplicavam os exercícios também de forma oral, baseados em perguntas e respostas. "Se acertassem, 'muito bem'; caso errassem, castigos. Ao fundo do salão ficava o mestre corrigindo os exercícios, atribuindo-lhes notas ou até mesmo cochilando" (SIQUEIRA, 2000, p.199).

O método, no Brasil, foi implantado pela Lei das Primeiras Letras de 15 de outubro de 1827 , cujo artigo $4^{\circ}$ expressa a proposta metodológica: As escolas serão de ensino mútuo nas capitais das provinciais; e serão também nas cidades, vilas e lugares populosos delas, em que for possível se estabelecerem.

De acordo com os estudos feitos por Elizabeth Madureira Siqueira (2000), o método do ensino mútuo, propriamente dito, não chegou a ser implantado nas escolas primárias de Mato Grosso, ainda que, segundo a autora, foi inserido, em Mato Grosso, um método semelhante denominado simultâneo. A rejeição ao ensino mútuo estava relacionada, diretamente, com a forma violenta com que os decuriões, com o consentimento do professor, aplicavam os castigos, além da falta de contato direto com o professor. Apesar dos castigos físicos e morais estarem presentes, neste período nas escolas primárias "chocava-se frontalmente com os preceitos dos 'modernos' castigos, já presentes na legislação brasileira de 1827” (SIQUEIRA, 2000, p.202).

Essas práticas pedagógicas eram utilizadas como estratégias pelos professores e até mesmo pelo Estado com a finalidade de incutir e propagar alguns valores e princípios para a massa analfabeta e, assim, atingir a sociedade como um todo. Ainda se pode verificar que os castigos estavam presentes como componente pedagógico na Lei de 15 de outubro de 1827: Art. 15. Estas escolas serão regidas pelos estatutos atuais no que se não opuserem à presente lei, os castigos serão os praticados pelo método de Lancaster.

Os professores e os representantes do Estado acreditavam que os castigos seriam um dos dispositivos mais eficazes para se formar, "endireitar" e civilizar crianças e adultos, pois julgavam que tal punição levaria ao repensar dos atos, transformando-os no mais próximo do cidadão idealizado para compor a sociedade.

Recorre-se ao Regulamento da Instrução Pública da Província de Mato Grosso, de 13 de Fevereiro de 1878, que estava em vigor no ano que o Professor Rodrigues informa ter sido vítima do uso da palmatória, para conferir quais eram os castigos aceitos no contexto escolar.

Artigo 149 - Os professores públicos de instrução primária e secundária poderão impor a seus alunos as seguintes penas:

$\S 1^{\circ}$ - Repreensão em particular.

$\S 2^{\circ}$ - Repreensão pública na aula.

$\S 3^{\circ}$ - Castigos vexatórios, como ficar de pé ou de joelhos.

$\S 4^{\circ}$ - Retenção na escola por 2 horas.

$\S 5^{\circ}$ - Trabalhos fora das horas letivas.

Artigo 150 - No caso de serem improfícuos os meios estatuídos para conter o aluno no cumprimento de seus deveres, será isto comunicado ao pai ou educador para este providenciar sobre maiores castigos. (PROVÍNCIA de Mato Grosso. Regulamento da Instrução Pública de 13 de Fevereiro de 1878)

Os castigos físicos, como a utilização da palmatória, não eram permitidos ou, pelo menos, não aparecia dentre as reprimendas, que deveriam ser aplicadas no caso de 
desobediência às regras escolares.

A reforma que estava em vigor no período em que Rodrigues cursava os estudos primários era a Reforma Leôncio de Carvalho aprovada pelo Decreto $\mathrm{n}^{\circ} 7247$ de 19 de Abril de 1879. O ensino primário era dividido em duas partes o $1^{\circ}$ grau era o ensino elementar e o $2^{\circ}$ grau era considerado o primário superior, já que proporcionava ao aluno dar continuidade aos estudos elementares. Entretanto, a legislação mato-grossense não estava em sintonia com as orientações da época, pois não previa o estudo de todas as disciplinas prescritas na Reforma Leôncio de Carvalho, de 1879.

A Reforma previa as seguintes disciplinas para o $1^{\circ}$ grau do Ensino Primário: Instrução moral; Instrução Religiosa; Leitura; Escrita; Noções de Cousas; Noções essenciais de gramática; Princípios elementares de aritmética; Sistema legal de pesos e medidas; Noções de história e geografia do Brasil; Elementos de desenho linear; Rudimentos de música, com exercícios de canto; Ginástica e Costura simples (para meninas). Já o $2^{\circ}$ grau do primário era composto pelas disciplinas: Princípios elementares de Álgebra e Geometria; Noções de Física, Química e História Natural com explicação de suas principais aplicações a indústria e ao uso da vida; Noções gerais dos deveres do homem e do cidadão, com explicação sucinta da organização política do império; Noções de lavoura e horticultura; Noções de economia social (para meninos) e Trabalhos de agulha (para meninas).

A figura, em continuidade, mostra o plano de estudo previsto para o ensino primário do $1^{\circ} \mathrm{e}$ do $2^{\circ}$ grau relativos aos alunos mato-grossenses:

Figura 3 - Extrato do Regulamento da Instrução Primária e Secundária da Província de Mato Grosso, de 1880

\section{Capítulo XII}

DO ENSINO E REGIME DAS ESCOLAS

Artigo 59 - O ensino nas escolas públicas compor-se-á:

$\S 1^{2}$ - De educação religiosa e doutrina cristã:

$\S 2^{2}$ - Leitura corrente;

$\S 3^{2}-$ Escritura corrente

$\S 40$ - Aritmética teórica e prática até decimais;

$\S 5^{2}$ - Sistema métrico decimal;

$\S 6^{2}-$ Trabalhos de agulha nas escolas do sexo feminino.

Artigo 60 - Estas disciplinas constituirão o ensino primário do le grau.

Artigo 61 - $\bigcirc$ ensino de $2^{\circ}$ grau desenvolverá, aperfeiçoará e completará o

ensino das matérias do 12 , adicionando a eles:

$\S 1^{2}$ - Catecismo:

$\S 2^{2}$ - Aritmética teórica e prática até proporções;

§ 32 - Gramática da língua nacional e análise dos clássicos portugueses:

$\S 4^{\circ}$ - Generalidades de Geografia e de História, especialmente da província de Mato Grosso:

$\S 5^{2}$ - Desenho linear.

Fonte: Siqueira (2000, p.163).

É notável que a lista de disciplinas trabalhadas no contexto escolar de Mato Grosso era inferior às trabalhadas na Corte. $\mathrm{O}$ fato é que não se pode deixar de observar que muitas disciplinas propostas pela legislação do Rio de Janeiro estavam voltadas para formar cidadãos, que precisava para suprir a necessidade da sociedade.

As noções de História e Geografia do Brasil que eram para serem trabalhadas no $1^{\circ}$ grau, segundo a legislação do município da Corte, no contexto mato-grossense, eram abordadas no $2^{\circ}$ grau, tendo como objetivo o estudo da província de Mato Grosso. A gramática e o desenho linear também eram objeto de estudo nas escolas mato-grossenses de $2^{\circ}$ grau, ao contrário das escolas da Corte, que os ministravam nas de $1^{\circ}$ grau. As demais disciplinas propostas para as escolas primárias de $1^{\circ}$ grau não constam na legislação de Mato Grosso, além do mais, de todas as disciplinas propostas para as escolas primárias de $2^{\circ}$ grau, somente o trabalho de agulha foi inserido no meio escolar mato-grossense.

Essas observações alertam que a cultura escolar propagada no Rio de Janeiro ainda não estava presente nas escolas do Mato Grosso, no entanto, a Reforma Leôncio de Carvalho estava presente na maneira que os administradores da província haviam se apropriado das concepções educacionais propostas por esta. De acordo com Chervel (1990), a escola não coloca em prática algumas sugestões - "intenções" - não por incapacidade de ensinar, mas porque sua finalidade não está voltada para aquela orientação e se colocar em ação outros "saberes eruditos", que não estão relacionados com o seu verdadeiro papel, não poderá cumprir sua missão. Sob esta compreensão, nota-se que os dirigentes da província de Mato Grosso inseriram no contexto escolar primário as disciplinas que acreditavam serem necessárias para o público, que frequentaria as escolas da província. Sendo assim, as disciplinas que Rodrigues teve acesso, durante sua trajetória escolar primária, estão listadas na figura anterior.

Logo após o término do Ensino Primário, matriculou-se no Liceu Cuiabano para iniciar seus estudos secundários. No segundo ano do curso secundário, Rodrigues (1959, p.14) descreve que:

[...] tive como professores: de português, José Magno da Silva Pereira; de francês e inglês, João Pedro Gardés, que tudo lecionava; de Geografia, Francisco da Costa Ribeiro; de Aritmética, o Dr. Antonio Corrêa da Costa, de Filosofia, o cidadão francês Eduardo Poyart e de Álgebra e Geometria José Estevão Corrêa.

Nos textos em que Firmo José Rodrigues registra suas recordações, sempre que trata dos professores, que fizeram parte da sua formação intelectual, destaca, entre eles, o professor José Estevão Corrêa, um personagem importante no contexto da instrução pública de Mato Grosso. Entre os elogios a esse professor de Matemática, foi possível resgatar, através das memórias de Rodrigues, o quanto este professor era dedicado à educação: "José Estevão Corrêa, professor do Liceu Cuiabano e, inegavelmente, um educador hábil, organizou com os seus alunos de Matemática, uma trupe teatral, que muitos espetáculos deu naquele teatro" (RODRIGUES, 1969, p.41).

Nesta passagem, se percebe que o professor José Estevão Corrêa, além de ser professor de Matemática, preocupava-se com a realização de uma atividade diferenciada por parte dos alunos. Na visão de Rodrigues, o tempo que José Estevão 
dedicava dirigindo peças teatrais aos estudantes do Liceu, auxiliava o aprimoramento da oratória deles, fazendo-o de maneira divertida. Rodrigues ainda ressalta que, apesar deste professor ter a função de ensinar os primeiros rudimentos matemáticos aos alunos, ele contribuía, de maneira significativa, através do palco para a cultura das letras, diminuindo o número de reprovados do Liceu Cuiabano.

No mundo contemporâneo, entende-se que a oratória, que Rodrigues registra em seus textos, seria a capacidade dos alunos se expressarem através da fala e a estratégia pedagógica adotada pelo professor José Estevão, poderia ser chamada, hoje, de diversificação das atividades curriculares, mantendo o objetivo de ensinar a Matemática. Este evento, de certo modo, mostra que, naquele tempo, existiam professores preocupados em articular o currículo humanista com o currículo científico.

Ao ler os documentos oficiais da época, pode-se afirmar que este professor, pelo qual Rodrigues tinha certa admiração, era dedicado e esforçado, em sua profissão, dessa maneira, assim sendo, tenta-se fazer uma breve biografia do professor José Estevão Correa para entender a sua contribuição para a Matemática escolar de Mato Grosso.

$\mathrm{Na}$ revista Instituto Histórico e Geográfico de Mato Grosso, publicada no ano de 1999, teve-se acesso aos dados biográficos do Professor José Estevão Corrêa através do discurso feito pelo seu bisneto, Afrânio Estevão Corrêa. De acordo com seus escritos, o educador José Estevão Corrêa nasceu em Cuiabá no dia 02 de agosto de 1840 e faleceu no dia 12 de outubro de 1917. Aos 18 anos, foi nomeado para o quadro da tesouraria da Fazenda, permanecendo até 1889 , aposentando-se na função de contador. No entanto, em 1870, começou a ter atividades paralelas a esta profissão, assumiu a cadeira de Matemática no Seminário Episcopal e, no mesmo ano, foi nomeado deputado provincial da Assembleia Legislativa, conciliando essas atividades por dezenove anos.

Mesmo com tantos compromissos, pode-se constatar, nos escritos de seu bisneto e nos relatos do professor Rodrigues, a sua plena dedicação ao magistério. Foi uma figura importante para a instrução pública de Mato Grosso e para os cursos do Ensino Secundário da então província. Lecionou Matemática nas três principais instituições do Mato Grosso, vindo a assumir a cadeira de Matemática do curso secundário, anexo ao Seminário Episcopal, aos 29 anos e, ali, permaneceu atuando por quase meio século. No Liceu Cuiabano, começou a reger aulas desde a criação da instituição até seus últimos dias e, na Escola Normal, lecionou a mesma cadeira por seis anos.

A atuação deste professor não ficou somente restrita à cadeira que ministrava aulas, na homenagem prestada pelo professor Felogênio Correa, pode-se verificar que ele dedicouse de tal maneira à instrução pública mato-grossense ao ponto de ser regulamentador do Departamento da Instrução Pública, Inspetor Escolar da Capital, Diretor do Liceu Cuiabano e

\section{Diretor-Geral da Instrução Pública.}

Durante quase meio século da sua permanência na atividade do magistério, não houve no departamento do ensino uma só iniciativa, um só reforma, uma nova fundação de escola, que não tivesse a sua sempre acatada colaboração, só imitada pela colaboração sábia e prudente de Ernesto Camilo Barreto. Foi o regulamentador do departamento de Instrução Pública durante decênios, professor de diversas cadeiras, Inspetor Escolar da Capital, Diretor do Liceu Cuiabano e DiretorGeral da Instrução Pública, deixando em todos esses lugares agradável memória da sua passagem. Grande amigo de festas e recompensas escolares, incentivava-as com frequência nas suas numerosas visitas a estabelecimentos de ensino públicos e particulares, não poupando esforços para estimular a infância estudiosa. (REVISTA INSTITUTO HISTÓRICO E GEOGRÁFICO DE MATO GROSSO, 1999, p.152).

Personagem importante no contexto mato-grossense, intelectual que contribuiu de maneira significativa nos âmbitos sociais e políticos, professor dedicado, ele marcou as memórias de seu aluno no Liceu Cuiabano, que se apropriou, de alguma forma, das práticas do professor Estevão. Suas memórias revelam, ainda mais, sobre esse educador, indicando um elemento fundamental na cultura escolar, o livro didático que era utilizado em suas aulas de Álgebra: "José Estevão sabia de cor toda a álgebra de Ottoni” (RODRIGUES, 1959, p.14).

Firmo José Rodrigues cursou o último ano do Ensino Secundário, em 1888, sendo assim, ainda estava em vigor a Reforma Leôncio de Carvalho e vigia o Programa de Ensino do Colégio de Pedro II para o ano de 1882. Houve acesso a esse programa por meio do livro Programa de Ensino da Escola Secundária Brasileira, que traz as propostas prescritas do período compreendido entre 1850 a 1951, de Ariclê Vechia e Karl Michael Lorenz, publicado em 1998.

Rodrigues (1959, p.14) observa que: "O curso era de seis anos e, durante este tempo, o aluno frequentava o de latim, para fazer exame final [...]", dentre esse período de seis anos a Álgebra deveria ser trabalhada no $3^{\circ}$ ano, composta por $^{2}$ :

Algebra: Emprego dos signaes algebricos, e suas consequencias principaes. Estudo comparativo das operações fundamentaes e bem assim das potencias e raizes que se referem ao $2^{\circ}$ gráo Propriedades geraes dos numeros. Equações do $1^{\circ}$ e $2^{\circ}$ gráos a uma incognita. Da eliminação nas equações do $1^{\circ}$ gráo a muitas

incognitas. Analyse indeterminada do $1^{\circ}$ gráo entre duas variaveis. Discussão dos problemas e equações do $1^{\circ}$ e $2^{\circ}$ gráos a uma incognita. Problemas. Exercicios sobre calculo algebrico (VECHIA; LORENZ, 1998, p.97-98).

As orientações trazem que o livro adotado era Elementos de Álgebra, escrito pelo Bacharel Luiz Pedro Drago. Outra vez, depara-se com o não segmento das orientações propostas, já que o livro de Álgebra usado pelo professor de Rodrigues era o livro de Cristiano Benedito Ottoni, proposto no programa de ensino do ano de 1856. Pode-se inferir que, em sua formação, o professor José Estevão Correa foi instruído por meio do livro de Ottoni, no entanto, nada se pode afirmar. A questão

2 Manteve-se a escrita conforme o original. 
é que ele utilizava essa obra em suas aulas e que, segundo Rodrigues (1959, p.15), bastava saber a Álgebra de Ottoni para ser aprovado na disciplina.

Entre os alunos de escola, salientava-se um preto, chamado Agostinho Lopes de Souza que, em álgebra, se não tinha raciocínio, tinha a facilidade de decorar dezenas de páginas do Ottoni. E era admirável, como ele decorava toda a discussão do 'problema dos correios', sem alterar uma vírgula. Isto aliás bastava à exigência do professor José Estêvão.

Terminados os estudos no Liceu Cuiabano, Rodrigues tentou fazer alguns exames de preparatórios ${ }^{3}$ e, nesse mesmo tempo, colaborava com um jornal, procurou arrumar empregos, como nada conseguiu, assim que surgiu o primeiro concurso, ele o fez. Foi, desse modo, que iniciou a sua carreira docente como professor efetivo da cadeira de instrução pública primária da então freguesia de Santo Antônio do Rio Abaixo. Em janeiro de 1890, o primeiro presidente do Estado de Mato Grosso, Antônio Maria Coelho, expediu, por meio do Palácio do Governo de Cuiabá, um Ato nomeando o referido professor mato-grossense. Esta localidade, na qual o professor Rodrigues iniciou a sua carreira docente, corresponde ao atual município de Santo Antônio de Leverger, distante apenas 27 quilômetros de Cuiabá.

No ano em que Rodrigues principiou a carreira como professor, o Estado estava ainda se adaptando à mudança entre o fim do Império e início da República. A reforma de Ensino que estava em vigor ainda era a Leôncio de Carvalho, já que a reforma, proposta por Benjamin Constant, foi aprovada somente em 22 de novembro de 1890. E o regulamento que permanecia vigorando era o Regulamento da Instrução Primária e Secundária da Província de Mato Grosso, de quatro de março de 1880. Assim, os conteúdos que o professor Firmo José Rodrigues deveria ensinar aos seus alunos eram os mesmos, que lhe foram ensinados em seu tempo escolar.

Todavia, ele não permaneceu muito tempo nesse concurso e o argumento que ele traz em seu texto é que "o Gen. Antônio Maria Coelho, que, se como militar foi um bravo, na campanha do Paraguai, na administração do Estado foi um desastre. Até hoje ainda não recebi os vencimentos a que fiz jus, como professor em S. Antônio, em 1890" (RODRIGUES, 1959, p.17).

Voltando a Cuiabá o professor mato-grossense tentou trabalhar na venda de propriedade de seu pai, no entanto, não se adaptou e tentou incorporar-se ao exército, “[...] com destino à guarnição do Rio de Janeiro" (RODRIGUES, 1959, p.17). Contudo, Rodrigues não foi feliz em sua primeira tentativa, sendo impedido de ingressar no exército por causa de sua magreza, julgado, pelo médico, como inapto para serviços militares.

A vontade e a esperança que ele tinha de estudar em uma academia superior não o deixaram desistir. Passou por uma nova inspeção, três meses depois, e foi assim que conseguiu assentar praça ${ }^{4}$, no dia 18 de setembro de 1890 . Firmo José Rodrigues estudou, a partir dessa data, na Escola Militar da Praia Vermelha.

Encontra-se, dentre os vários de cadernos de registros do Rodrigues, as suas anotações manuscritas sobre as aulas positivistas que tinha nessa época, sendo estas proferidas por Benjamin Constant. Não se pode deixar de ressaltar que os positivistas eram contra a monarquia, eram a favor da separação entre o Estado e a Igreja e, também, eram abolicionistas.

De acordo com Lemos (1997), Benjamin Constant foi oficial do exército brasileiro e também professor de Matemática em diversas escolas. Instruído em sua formação militar pelas ideias de Auguste Comte, seguiu fielmente a filosofia positivista e a propagou. Sua atuação como militar não ficou restrita a Guerra do Paraguai (1865-1870), uma vez que atuou em vários outros segmentos militares. Contudo, o movimento que lhe deixou conhecido como fundador da República, foi citado por Rodrigues como o movimento que renunciava a monarquia. Benjamin Constant atuou ainda em ministérios, na administração de Estados e também em cargos federais no Executivo e no Legislativo. Além disso, propôs uma reforma de ensino aprovada pelo decreto $n^{\circ} 1075$ de 22 de novembro de 1890.

Depois de concluir os estudos na Escola Militar da Praia Vermelha, Rodrigues serviu o $8^{\circ}$ Batalhão de Infantaria na Alfândega de Corumbá, posteriormente, serviu o $2^{\circ}$ Batalhão de Artilharia e, de 1899 até 1911, trabalhou no Arsenal de Guerra. Em 1900, Rodrigues recebeu o diploma que lhe deu o título de Agrimensor, por meio do Decreto ${ }^{\circ} 330$ de 12 de Abril de 1890. Este decreto aprovou o regulamento que reorganizou o ensino nas escolas do exército, do qual Benjamin Constant Botelho de Magalhães foi um dos organizadores.

$\mathrm{O}$ artigo 36 do regulamento citado dava o direito ao título de Agrimensor a todos aqueles que concluíssem todo o curso geral. O curso geral tinha as seguintes disciplinas de Matemática ou que a envolvia: Geometria geral (até seu complemento algébrico), Cálculo diferencial e integral (estudo completo), Geometria descritiva (estudo completo) e Mecânica geral (composta por cálculos das variações e aplicações a máquinas). Assim, com um programa de ensino um tanto quanto denso no que diz respeito à Matemática, proporcionava aos agrimensores uma formação aprofundada, tornando-os hábeis para ensinar os conteúdos da referida ciência.

A primeira informação que se tem sobre a atuação de Rodrigues como professor, após os seus estudos militares foi que ele lecionou no Liceu Salesiano de Artes e Ofícios, em 1909 , ano que recebeu sua promoção de $1^{\circ}$ para $2^{\circ}$ tenente de Artilharia.

3 Os exames preparatórios eram necessários para prosseguir os estudos em nível superior, seriam os vestibulares, atualmente.

4 Incorporar-se ao exército. 
Dentre os textos didáticos do professor Rodrigues, se tem em mãos a caderneta de anotações das lições de Álgebra e Agrimensura, que ministrava no Liceu Salesiano São Gonçalo nos anos de 1910 e 1911. Esta caderneta possui o nome dos alunos com as respectivas notas das atividades propostas. Consta, também, a data de cada aula, em que foram trabalhados os conteúdos do programa de ensino, além dos exercícios propostos aos alunos do $4^{\circ}$ e $5^{\circ}$ ano do Liceu.

No dia quatro de abril de 1911, Rodrigues recebeu um ofício que solicitava o seu comparecimento para assumir o compromisso de se ocupar da cadeira de Física e de Química do Liceu Cuiabano, assim verifica-se que não somente ministrava aulas de Matemática, como também lecionava outras disciplinas.

Dentre os documentos que se tem, deste respectivo ano sobre seus estudos e textos didáticos, há um caderno de estudo de língua grega, contendo vários exercícios. Dessa forma, se pode pensar que o professor estava estudando a língua grega por conta própria, ou seja, praticava atividades autodidatas com o objetivo de enriquecer os seus conhecimentos intelectuais.

Em 1917, foi reconhecido, pelo Instituto Histórico e Geográfico de Mato Grosso, como intelectual regional de grande importância e, assim, concederam-lhe o diploma de sócio do Instituto.

A atuação de Firmo José Rodrigues como professor de Matemática fica somente evidente ao assumir a cadeira de Matemática no Liceu Cuiabano, que estava vaga. De acordo com os documentos de seu acervo pessoal, este fato aconteceu no dia 31 de janeiro de 1922. Obteve-se essa informação por meio da carta de convocação enviada pela diretoria da instituição e pode-se notar que o tratam como Major. A presença de militares e engenheiros, ainda neste período, era forte dentro das instituições, principalmente, na área da Matemática e, além do mais, a formação destinada às licenciaturas não existia até aquele momento.

A carreira dele como professor, nesta instituição e em outras como a Escola Normal e o Liceu Salesiano, foi frutífera, pode-se ver dentre os seus documentos que os seus alunos o admiravam e tinham grande afeto e respeito pelo professor de Matemática. Porém, na década de 1930, este professor quase pôs um fim em sua carreira. Surgiram várias instituições destinadas a organizar o ensino brasileiro. Viviase a Revolução de 1930 e, com a atuação de Getúlio Vargas no poder, foi criado, em 14 de julho de 1930, pelo Decreto ${ }^{\circ}$ 19.402, o Ministério da Educação denominado, naquela época, Ministério da Educação e Saúde Pública, tendo Francisco Campos como Ministro da Educação. No governo de Vargas foram aprovados vários decretos com o intuito de organizar o Ensino Secundário e Superior no Brasil, conhecidos como "Reforma Francisco Campos".

Em 1934, foi criada a Diretoria Nacional da Educação pelo Decreto $\mathrm{n}^{\circ}$ 24.439, de 21 de Junho de 1934. Este departamento tinha como objetivo: examinar as condições materiais dos educandários, bem como analisar as questões ligadas à formação e ao recrutamento do professorado, bem como a organização e a revisão do programa de ensino, a elaboração de textos para os cursos secundários e comerciais e, ainda, a fiscalização dos processos educativos e instrução em todo Pais.

Foi também, na década de 1930, que surgiram as primeiras instituições próprias para formar professores do Ensino Secundário. No entanto, os professores que já atuavam neste nível de ensino e não possuíam a formação adequada para esta profissão, poderiam continuar trabalhando, desde que fizessem o Registro de Professores, que foi instituído, em 1931, com o propósito de regulamentar esta profissão, quem não o fizesse, teria que abandonar a carreira.

De acordo com Bezerra (2008), para que as instituições de ensino secundário pudessem expedir certificados de conclusão deste nível de ensino que, nesta reforma, se tornava obrigatório aos alunos que quisessem adentrar ao Ensino Superior, era necessário que fizessem a solicitação ao Ministério da Educação e Saúde Pública, em que se analisaria se a instituição estava cumprindo as exigências previstas na Reforma Campos.

Bezerra (2008, p.27), ainda, ressalta que:

'Os requisitos mínimos' exigidos para a inspeção dos estabelecimentos de ensino expressavam a intenção do Ministério de Educação em padronizar desde a estrutura física do edifício escolar, suas instalações e condições de funcionamento até os materiais didáticos utilizados por disciplina e a qualificação do corpo docente, que deveria ser inscrito no Registro de Professores.

A todos os colégios do Ensino Secundário da época interessava expedir o certificado de valor oficial, assim, todo o corpo docente das instituições teria que se registrar. No entanto, tal registro não se limitava aos profissionais das instituições, que passariam pela inspeção, mas incluíam todos que exerciam a profissão no nível secundário.

O registro, primeiramente, tinha valor provisório e este só se tornaria de caráter definitivo se o professor passasse por um exame ou banca. Este registro provisório possibilitava permanecer lecionando apenas alguns anos, no entanto, ficou ativo durante muito tempo, mesmo depois da criação da primeira universidade do Brasil destinada à formação de docentes.

O Certificado de Registro Provisório de Professor de Rodrigues foi expedido no ano de 1936, mostrando, assim, que o Registro, que era para ser de caráter provisório, na sua criação em 1931, perdurou durante muito tempo para que os professores, que não obtinham diplomas de Ensino Superior pudessem continuar atuando no nível secundário.

Constatou-se que a atuação no magistério foi longa e, no espaço de tempo que esteve envolvido com o ensino, ocorreram várias reformas e mudanças, com as quais ele teve que se adaptar.

Ao escrever suas memórias, em um texto enriquecido com vários detalhes e escrito em um tom bem informal, o professor de Matemática, cuiabano, deixa transparecer que ele próprio considerava que seu destino era mesmo ser professor. 
Quem escreve estas linhas, por mais que torcesse, cumpriu seu destino: ser professor. Começou a vida como professor público da vila de $\mathrm{S}$. Antonio do Rio Abaixo, onde percebia o ordenado de $55 \$ 000$, que [...] nunca recebeu porque, durante o tempo que nessa função permaneceu, o Tesouro do Estado viveu apitando. Assentou praça, com destino à Cuiabá e aqui foi solicitado para dar lições particulares de matemática. E nunca mais o largaram; continua a ser professor, sem ao menos gozar umas férias. Também ele nunca precisou de repouso. (RODRIGUES, 1969, p.50)

Houve oportunidade de examinar, nos documentos, que essas memórias foram escritas nos últimos quatro anos de sua existência, entre 1940 e 1944, quando afirma que ainda continuava sendo professor. Ao que tudo indica, ele exerceu o magistério por cerca de meio século, pois conforme ele registra, ao ser convidado para ministrar aulas de Matemática, "nunca mais o largaram". Em outros termos, trata-se de uma longa trajetória de atuação na Educação Matemática escolar, mesmo que ele tenha permanecido alguns anos fora de Cuiabá para obter a sua formação na Escola Militar do Rio de Janeiro (RODRIGUES, 1969).

Nota-se, neste esforço de investigar e de analisar as produções de Rodrigues, que ele ainda estava impregnado com a cultura escolar da sua época de estudante, reproduzindo-a em uma época em que a Matemática havia sofrido modificações e possuía outros objetivos.

\section{Conclusão}

Face a essa exposição, por certo, uma questão importante é indagar em que medida os trabalhos que tomam como foco principal personagens têm elaborado uma história sobre a educação matemática. Cabendo, sem dúvida, autoavaliação da proposta deste texto. Neste trabalho foram utilizadas fontes que, usualmente, são empregadas em pesquisas brasileiras sobre história da formação/atuação de professores, como, por exemplo, documentos escolares, diários de classe, livros, regimentos, regulamentos, relatórios de inspetores de ensino, fotografias, além dos testemunhos escritos do professor em foco. Essas fontes participaram, de maneira relevante, e tornaram possível essa pesquisa, pois as conexões e relações que estas proporcionaram, revelaram elementos fundamentais da formação que o professor, que ensinava Matemática no Mato Grosso Uno possuía, bem como elementos da educação matemática da época. Isso se deve à natureza das disciplinas escolares, entendidas neste trabalho como um conjunto de práticas e discursos que visam transmissão de saberes, que contribuíram para produzi-las.

Vale ressalvar que apesar do foco ter sido um dos professores que atuou no Estado em questão, os documentos, as ausências de documentos, as relações que foram construídas com todas as fontes, permitiram não somente tecer compreensões sobre o próprio personagem, mas, foi possível tecer compreensões mais gerais da educação matemática, sobre outros professores, sobre os movimentos e as reformas educacionais.

Assim, nota-se que ao final do século XIX, o método utilizado pelas escolas era o método simultâneo e castigos como a palmatória faziam parte do contexto escolar. Observase que houve mudanças de reformas significativas, como a de Leôncio de Carvalho, de Benjamin Constant e, por fim, a de Francisco Campos, cada uma defendendo os interesses de quem estava no poder, tentando inculcar uma cultura escolar a partir do colégio modelo.

Outro fato que foi possível observar é de que as ideias positivistas permeavam a época do fim do Império e do início da República e que de alguma forma essas ideias também circulavam no contexto escolar, já que professores de Matemática, que foram militares como o Firmo, nesta época, em que tiveram aulas proferidas pelo próprio Benjamin Constant com uma formação extremamente positivista.

Já na década de 1930, com a reforma Francisco Campos se nota o surgimento das primeiras instituições próprias para formar professores do Ensino Secundário e o Registro de Professores, que visava regulamentar a profissão, com a ideia de que os professores precisariam se atualizar em cursos específicos das disciplinas que ministravam.

Indo além, foi por meio das análises apresentadas nas quais se verificam que a formação dos professores, que ensinavam Matemática ao final do século XIX e início do século XX que tinha, era basicamente de cunho militar, senão engenheiros ou contadores. Desse modo, havia grande presença de engenheiros, militares e políticos dentro das instituições públicas de ensino, principalmente, no que diz respeito aos professores que ensinavam Matemática. Essa afirmação é notável, desde o registro que se tem do professor que assumiu uma das primeiras cadeiras destinadas a Matemática no Mato Grosso Uno, já que tal professor foi o Tenente João Baptista Castro Morais Antas, que estudou na Acadêmica Militar da Corte, tinha formação em Engenharia Civil e foi um dos primeiros doutores em Ciências e Matemática.

Ao longo da trajetória do professor Firmo se teve acesso a informação de alguns de seus professores de Matemática. Destaca-se José Estevão Corrêa, professor de Álgebra e Geometria do Firmo no Ensino Secundário, além de ter sido contador, funcionário na tesouraria da Fazenda e deputado. Outro professor de Matemática do Firmo que marcou sua trajetória, foi Benjamin Constant também oficial do Exército Brasileiro e atuou na administração de Estados em cargos federais no Executivo e no Legislativo.

E, por fim, se tem o próprio Firmo José Rodrigues, militar, agrimensor, político e professor. No modo de ver, tanto a sua posição como militar, político e intelectual condicionaram a atuação como educador. Suas ações educativas estavam relacionadas com as causas sociais, uma expressão de um compromisso com a mocidade de seu estado, que ele mesmo se dispôs a fazer, inserindo-se no contexto militar, escolar, social e político. Além disso, contribuiu para revistas e jornais, que circulavam em sua época, sempre se interessando em buscar no passado, as histórias de seu Estado, como tentativa de manter vivas as lembranças e os acontecimentos do presente. 
Dessa forma, foi possível compreender os caminhos que a Matemática escolar estava percorrendo nos anos de sua formação, as reformas de ensino e, do mesmo modo, estudar os regulamentos que regiam a instrução pública e a instrução militar naquele momento. Tais informações forneceram elementos, que podem conduzir à constituição da Matemática escolar e, também, a analisar como o professor do ensino secundário carregou traços de sua formação no trabalho com o magistério.

\section{Referências}

BARONI, R.L.S.; MILLER, C.P. Instituição do doutorado em Matemática no Brasil: Escola Militar do Rio de Janeiro, 1842. Acta Scientiarum Hum. Soc. Sci., v.30, n.1, p.97-104, 2008.

BEZERRA, A.C.D.R. Apostolado cívico e trabalhadores do ensino: história do magistério do ensino secundário no Brasil (1931-1942). 2008. 251f. Dissertação (Mestrado em Educação) - Universidade Federal Fluminense, Niterói, 2008.

BLOCH, M. A apologia da história ou o oficio do historiador. Rio de Janeiro: Jorge Zahar, 2001.

BRASIL. Decreto n. 330 de 12 de Abril de 1890. Regulamento que reorganiza o ensino nas escolas do Exército. Disponível em: www.senado.gov.br/sicon.

CHARTIER, R. O mundo como representação. Estudos Avançados IEA - USP, v.11, n.5, p.173-191, 1991.

CHERVEL, A. Historia das disciplinas escolares: reflexões sobre um campo de pesquisa. Teoria Educ., n.6, p.177-229, 1990.

DE CERTEAU, M. A invenção do cotidiano: artes de fazer. Petróplolis: Vozes, 2008.

FREIRE, Z.P.M. Fala dirigida á Assembléa Legislativa Provincial de Mato Grosso na abertura da sessão ordinária no ano de 1844 pelo exm. senhor presidente da provincia, o coronel Zefirino Pimentel Moreira Freire. Cuiabá, Typ. Provincial, 1844. Disponível em: http://www.crl.edu/brazil/provincial

GINZBURG, C. O queijo e os vermes: o cotidiano e as ideias de um moleiro perseguido pela inquisição.São Paulo: Companhia das Letras, 2006.

JULIA, D. A cultura escolar como objeto histórico. Rev. Bras.
História Educ., n.1, p.8-43, 2001.

LEMOS, R.L.C.N. Benjamin Constant: biografia e explicação histórica. Rev. Estudos Históricos, v.10, n.19, p.67-82, 1997.

MARTINS-SALANDIM, M.E. A interiorização dos cursos de Matemática no estado de São Paulo: um exame da década de 1960. 379f. Tese (Doutorado em Educação Matemática) - Universidade Estadual Paulista, Rio Claro, 2012.

MOACYR, P. A instrução e as províncias. Subsídios para a história da educação no Brasil (1834-1889). São Paulo: Editora Nacional, 1939.

NOBRE, S.R; TEIXEIRA, M.V.; BARONI, R.L.S. A investigação científica em história da matemática e suas relações com o programa de pós-graduação em educação matemática. In: BICUDO, M.A.V.; BORBA, M.C. (Org.). Educação matemática: pesquisa em movimento. São Paulo: Cortez, 2004. p.164-185

PROVÍNCIA de Mato Grosso. Regulamento da Instrução Pública de 13 de Fevereiro de 1878. APMT - Regulamentos. Cuiabá. 1878 .

REVISTA INSTITUTO HISTÓRICO E GEOGRÁRICO DE MATO GROSSO. Cuiabá. Tomos CXLVII. Ano LXXI.1999.

REZENDE, E.R. Fala dirigida á Assembléa Legislativa Provincial de Mato Grosso na abertura da sessão ordinária no ano de 1839 pelo exm. senhor presidente da provincia, Estevão Ribeiro de Rezende. Cuiabá, Typ. Provincial, 1839. Disponível em: http:// www.crl.edu/brazil/provincial

RODRIGUES, F. Figuras e coisas de nossa terra. Cuiabá: Mercúrio, 1959.

RODRIGUES, F. Figuras e coisas de nossa terra: $2^{\circ}$ volume. Cuiabá: Escola Técnica Federal de Mato Grosso, 1969.

SIQUEIRA, E.M.. Luzes e sombras: modernidade e educação pública em Mato Grosso (1870-1899). Cuiabá: INEP/COMPED/ EdUFMT, 2000.

SCHUBRING, G. Pesquisar sobre a história do ensino da matemática: metodologia, abordagem e perspectivas. 2005. Disponível em: http://spiem.pt/DOCS/ATAS ENCONTROS/2004/2004_01_GSchubring.pdf. Acesso em: $2 \overline{3}$ jan. 2017.

VECHIA, A.; LORENZ, K.M. Programa de ensino da escola secundária brasileira: 1850-1951. Curitiba: Do Autor, 1998. 